\title{
Effect of topical dorzolamide on rabbit central corneal thickness
}

G.C. Almeida Jr. ${ }^{1}$ and S.J. Faria e Souza ${ }^{2}$

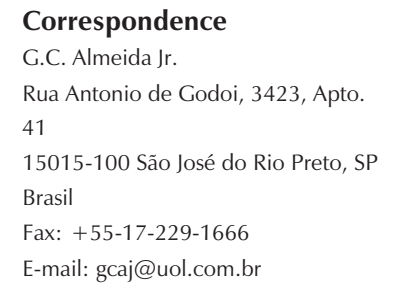

Correspondence

G.C. Almeida Jr.

Rua Antonio de Godoi, 3423, Apto.$$
41
$$

15015-100 São José do Rio Preto, SP Brasil

Fax: +55-17-229-1666

E-mail: gcaj@uol.com.br

Publication supported by FAPESP.

$\ldots \ldots \ldots \ldots \ldots \ldots$

Received October 26, 2004 Accepted October 31, 2005

\author{
${ }^{1}$ Departamento de Especialidades Cirúrgicas, Oftalmologia, \\ Faculdade de Medicina Estadual de São José do Rio Preto, \\ São José do Rio Preto, SP, Brasil \\ ${ }^{2}$ Departamento de Oftalmologia e Otorrinolaringologia, \\ Faculdade de Medicina de Ribeirão Preto, Universidade de São Paulo, \\ Ribeirão Preto, SP, Brasil
}

\begin{abstract}
Our objective was to study the effect of dorzolamide on corneal hydration in an 18-week controlled experiment using ultrasonic pachymetry. Twenty-eight male rabbits were divided randomly into four groups. The 7 rabbits in each group received eye drops containing either $2 \%(\mathrm{w} / \mathrm{v})$ dorzolamide or placebo in their right eye, or in their left eye. The $2 \%$ dorzolamide rabbits were treated every $8 \mathrm{~h}$. Fellow eyes are defined as eyes which did not receive either dorzolamide or placebo. The study was blind for both the person who applied the drug and the one who performed the pachymetry. The effect of treatments is reported on the basis of the percentage of pachymetric variation compared to the measurement made before drug application. There was no significant difference $(\mathrm{P}=0.061)$ in pachymetric variation between dorzolamide $(-4.42 \pm 11.71 \%)$ and placebo $(2.48 \pm 9.63 \%)$. However, there was a significant difference $(\mathrm{P}=0.0034)$ in pachymetric variation between the dorzolamide fellow eyes $(-7.56 \pm 10.50 \%)$ and the placebo $(-4.42 \pm 11.71 \%)$. In conclusion, dorzolamide did not increase the corneal thickness in rabbits.
\end{abstract}

Dorzolamide is a potent topical carbonic anhydrase (CA) inhibitor (1), which reduces the formation of bicarbonate and, consequently, the aqueous humor (2). This drug has caused a significant reduction of ocular pressure in animal models of ocular hypertension (3) and has been used clinically in glaucoma patients since 1995 (4).

Because endothelial CA plays a role in the mechanism of fluid transportation (5), there is some concern that the use of dorzolamide may have a deleterious effect on the cornea. For example, Wilkerson et al. (6) observed that corneal thickness (CT) in-
Key words

- Dorzolamide

- Corneal thickness

- Carbonic anhydrase

inhibition

- Ultrasonic pachymetry

.................... creased in a group using dorzolamide, while other study did not show differences in CT between users and non-users of dorzolamide (4). However, Konowal et al. (7) described 9 cases of irreversible corneal decompensation after the use of dorzolamide. In spite of a single report that dorzolamide did not increase the CT of rabbits after 3 months of use (8), we extended the treatment time to 18 weeks.

The objective of the present study was to evaluate the effect of topical $2 \%$ dorzolamide applied in the form of eye drops (ED) over a period of 18 weeks on the CT of adult rab- 
bits, using an ultrasound pachymeter as an indicator of endothelial function.

The study was conducted on 28 male New Zealand white rabbits weighing more than $3.0 \mathrm{~kg}$ and older than 16 weeks. The animals were kept in the Animal House of the State Medical School of São José do Rio Preto (FAMERP), with free access to food and water. They were treated according to the norms of the Brazilian Animal Experimentation Code (COBEA) (9). The experiment was approved by the Institution's Ethics Committee on Animal Experimentation. The rabbits were numbered from 1 to 28 and randomly divided into two groups of 14 animals each.

One group received ED of 2\% dorzolamide $\left(\right.$ Trusopt $^{\circledR}$, Merck, Sharp \& Dohme, West Point, PA, USA) in one of the eyes and nothing in the other. The control group received ED of a placebo in one eye and nothing in the other. In each group, the choice of the eye receiving ED was made using a table of random numbers. Consequently, four groups of 14 eyes were formed as follows:

Dorzolamide group (DG): 7 right eyes and 7 left eyes treated with Trusopt ${ }^{\circledR}$; dorzolamide fellow eye group (DFEG): 7 right eyes and 7 left eyes with no treatment; placebo group (PG): 7 right eyes and 7 left eyes treated with placebo ED; placebo fellow eye group (PFEG): 7 right eyes and 7 left eyes with no treatment.

Placebo ED developed by the Pharmaceutical Sciences course of UNESP, Araraquara, SP, Brazil, was chosen, with the following composition: 0.25 g hydroxyethyl cellulose, $1.83 \mathrm{~g}$ glucose, citrate buffer, and $0.01 \%$ benzalkonium. The product has a $\mathrm{pH}$ $=7.4$ and osmolarity ranging from 300 to $330 \mathrm{mOsm}$. The final product of the placebo was provided by the Ophthalmos ${ }^{\circledR}$ Pharmaceutical Laboratory (São Paulo, SP, Brazil).

The composition of Trusopt ${ }^{\circledR}$ is as follows (10): $22.3 \mathrm{mg} / \mathrm{mL}$ dorzolamide hydrochloride (20 mg dorzolamide) plus the fol- lowing inactive ingredients: hydroxyethyl cellulose, mannitol, sodium citrate dihydrate, sodium hydroxide, water for injection, and $0.0075 \%$ benzalkonium chloride as a preservative. The final product has a $\mathrm{pH}=5.6$ and osmolarity of 262 to $330 \mathrm{mOsm}$.

The ED were instilled in each animal three times daily $(8 / 8 \mathrm{~h})$ for 18 weeks. The person who instilled the ED had no knowledge of the pachymetric measurements performed by the investigator.

To measure CT, a Humphrey ${ }^{\circledR}$ Instruments Ultrasound Pachymeter model 855 (San Leandro, CA, USA) was used with a transducer frequency of $12 \mathrm{MHz}$, and velocity adjusted to $1580 \mathrm{~m} / \mathrm{s}$. Five measurements were obtained from the central region of the cornea of all rabbits and the mean for each eye was calculated. During the measurements, anesthetic ED were not necessary since the rabbits did not present signs of discomfort during the procedure, and this technique had been validated in another study (11).

A total of 19 measurements were first performed before the use of any ED, followed by weekly evaluations for 18 weeks. The measurements were made at the same time (11 o'clock) and in the same order (from 1 to 28).

The apparatus was calibrated weekly. The study was blind and the same investigator performed the measurements, while a coworker wrote down the values obtained with the pachymeter.

The effects of treatment on CT were measured by means of a variable called the percent of pachymetric variation (PPV). For the calculation each measurement was subtracted from the corresponding initial pachymeter measurement, i.e., the measurement made before the initiation of treatment. Then, this difference was divided by the initial pachymetric measurement, and the result multiplied by 100 .

Analysis of variance (ANOVA) for repeated measurements was used to compare 
the DG and PG and the DFEG and PG, and to evaluate the differences between the measurements of the PPV of the corneas of the DG and DFEG, and of the PG and PFEG.

The matched $t$-test was used to compare the PPV measurements between the PG and the PFEG and between the DG and DFEG. For statistical analysis a level of $\alpha=0.05$ was taken to be significant.

Analysis of the PPV of the four different groups demonstrated that a mean reduction of the CT occurred in the DG and DFEG, while a slight increase occurred in the PG and PFEG (Table 1). There were no significant differences in mean PPV between the PG and PFEG by ANOVA or by the matched $t$-test. ANOVA of the mean PPV of the DFEG and PG showed a significant difference between groups ( $P=0.0034)$, as illustrated in Figure 1C.

Figure $1 \mathrm{~A}$ and $\mathrm{D}$ show that there was no difference between PG and PFEG. Figure 1B shows a reduction in corneal thickness which, however, was not statistically significant because the number of rabbits, 7 , was small. However, the matched $t$-test of the mean PPV values for both groups revealed a significant difference $(\mathrm{P}=0.0012)$, as shown in Figure 1.

The mean PPV of the DG was negative, whereas the mean PPV of PG was positive (Table 1). Using PG as control revealed that the mean PPV of the DG differed significantly from that of the PG only at a level of $7 \%(\mathrm{P}=0.0613)$. We expected to find greater $\mathrm{CT}$ in the DG than in the PG since experimental studies with thiadiazoles and benzothiazoles, which have CA inhibitory properties in vitro in endothelial corneal cells, showed an increase of 6 to $10 \%$ in CT (12). Therefore, we cannot explain why CT did not increase with the use of dorzolamide, but actually decreased.

The use of 18-week dorzolamide administration in healthy eyes, inhibiting the CA in the corneal endothelium might diminish the formation of bicarbonate. Perhaps this re- duction resulted in a compensatory reactive effect, maintaining corneal hydration as well as generating the paradoxical effect of CT reduction.

Some compensatory mechanisms of the corneal endothelium are known to exist, such as the increase in the $\mathrm{Na} / \mathrm{K}$-ATPase sites of the corneal endothelium under stress (13), the ability of endothelial cells to form tight junctions to maintain the endothelium barrier (14), and the ability of the endothelium to transfer the glucose metabolism of the carboxylic acid cycle to the hexose monophosphate pathway (15).

The DFEG, which did not receive any medication, presented PPV that was significantly different from the PG $(\mathrm{P}=0.0034)$. This could be explained by the existence of systemic mechanisms of corneal hydration regulation. These mechanisms acting on the fellow eye result in inverse effects, such as the reduction of the CT. This explanation is reasonable, since the cell membrane receptors in the endothelium, present in other cells, could interfere with the regulation of the endothelial pump activity (16).

The systemic absorption of the drug might cause some effect on the fellow eye. This, in our view, is more implausible because the plasma concentration of dorzolamide is nearly $1 / 200$ of that needed for systemic

Table 1. Percent pachymetric variation in the eyes of the groups studied over a period of 18 weeks.

\begin{tabular}{lrcc} 
Group & Mean \pm SD $(\%)$ & \multicolumn{2}{c}{ ANOVA } \\
\cline { 3 - 4 } & & - & $\mathrm{P}=0.061$ \\
& & Dorzolamide group & Placebo group \\
\hline Dorzolamide group & $-4.42 \pm 11.71$ & $\mathrm{P}=0.275$ & $\mathrm{P}=0.0034^{*}$ \\
Dorzolamide fellow eye group & $-7.56 \pm 10.50$ & $\mathrm{P}=0.061$ & - \\
Placebo group & $2.48 \pm 9.63$ & - & $\mathrm{P}=0.571$ \\
Placebo fellow eye group & $2.15 \pm 9.35$ & &
\end{tabular}

Data are reported as means \pm SD for 7 rabbits in each group. Dorzolamide group: the rabbits received eye drops of $2 \%$ dorzolamide every $8 \mathrm{~h}$ for 18 weeks. Dorzolamide fellow eye group: fellow eyes of the dorzolamide group with no treatment. Placebo group: the rabbits received an eye drop of a placebo every $8 \mathrm{~h}$ for 18 weeks. Placebo fellow eye groups: fellow eyes of the placebo group with no treatment.

${ }^{*} \mathrm{P}<0.05$ compared to the placebo group and dorzolamide fellow eye group (ANOVA). 
Figure 1. Graphic presentation of percent pachymetric variation (PPV) in the four groups studied over a period of 18 weeks. See legend to Table 1 for identification of the groups.
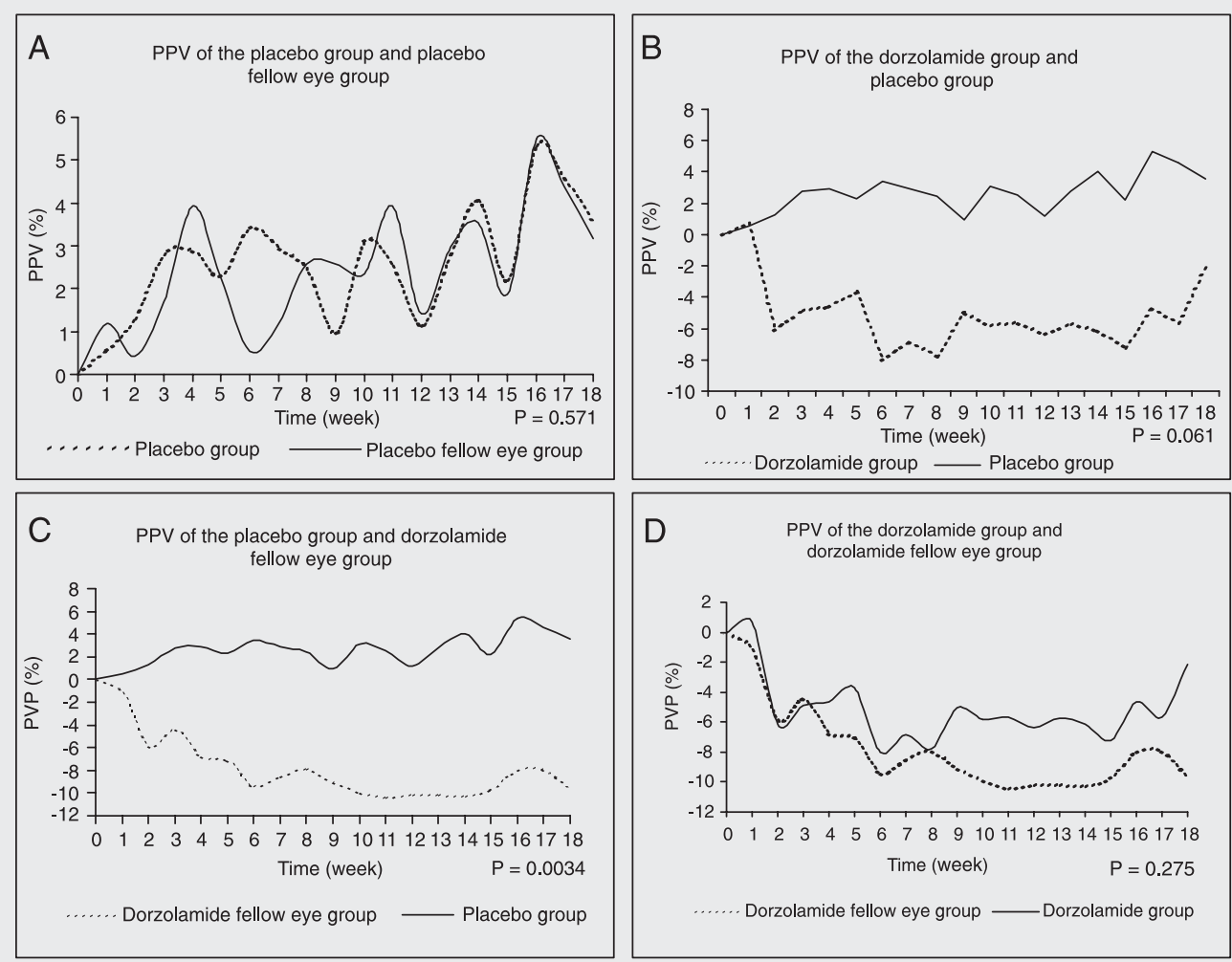

effects, as seen following acetazolamide administration. Therefore, there was no physiological effect of ocular dorzolamide, except on the eye itself (2).

The increase in the thickness of the human cornea with the use of topical dorzolamide was only reported in abnormal situations such as glaucoma $(6,17)$, ocular hypertension (6) and penetrating keratoplasties (7). It is possible that, under these conditions, the cornea treated with a carbonic anhydrase inhibitor could totally or partially lose the capacity to use its compensatory mechanisms. A study on healthy eyes using dorzolamide did not show an increase of CT (4). The results of the present study are almost similar to those of Gordon et al. (8). There was no increase of $\mathrm{CT}$, although there was some CT decrease mainly in DG and DFEG.

Although the rabbit cornea may be an appropriate in vitro model to study human transcorneal penetration of drugs (18), the results of the present study should be considered with caution since the rabbit cornea does not have Bowman's membrane (19) and the disposition of collagen in the Descemet's membrane is different (20).

To sum up, dorzolamide may interfere with the hydration regulation mechanism, decreasing the CT, since the reaction of the human eye is similar to the rabbit's. Further studies are needed to investigate if a longer use of dorzolamide can interfere with the control of corneal hydration. 


\section{References}

1. Baldwin JJ, Ponticello GS, Anderson PS et al. (1989). Thienothiopyran-2-sulfonamides: novel topically active carbonic anhydrase inhibitors for the treatment of glaucoma. Journal of Medicinal Chemistry, 32: 2510-2513.

2. Maren TH, Conroy CW, Wynns GC et al. (1997). Ocular absorption, blood levels and excretion of dorzolamide, a topically active carbonic anhydrase inhibitor. Journal of Ocular Pharmacology and Therapeutics, 13: 23-30.

3. Wang RF, Serle JB, Podos SM et al. (1990). The ocular hypotensive effect of the topical carbonic anhydrase inhibitor L-671 152 in glaucomatous monkeys. Archives of Ophthalmology, 108: 511-513.

4. Lass JH, Khosrof SA, Laurence JK et al. (1998). A double-masked, randomized, 1-year study comparing the corneal effects of dorzolamide, timolol, and betaxolol. Archives of Ophthalmology, 116: 10031010.

5. Wigham CG, Turner HC, Ogbuehi KCC et al. (1996). Two pathways for electrogenic bicarbonate ion movement across the rabbit corneal endothelium. Biochimica et Biophysica Acta, 1279: 104-110.

6. Wilkerson M, Cyrlin M, Lippa EA et al. (1993). Four-week safety and efficacy study of dorzolamide, a novel, active topical carbonic anhydrase inhibitor. Archives of Ophthalmology, 111: 1343-1350.

7. Konowal A, Morrison JC, Brown SVL et al. (1999). Irreversible corneal decompensation in patients treated with topical dorzolamide. American Journal of Ophthalmology, 127: 403-406.

8. Gordon LR, Bailly Y, Durand-Cavagna G et al. (1997). Preclinical ocular irritation findings with dorzolamide hydrochloride. Journal of Toxicology. Cutaneous and Ocular Toxicology, 16: 9-17.

9. Legislation and Ethics of the Brazilian Animal Experimentation Code (COBEA). The COBEA page. [http://www.cobea.org.br/etica.htm]. Accessed March 12, 2005.

10. Rx List The internet drug index home page. The dorzolamide description. [http://www.rxlist.com/cgi/generic/dorzolamide.htm]. Ac- cessed March 22, 2005.

11. Chan-Ling T, Payor S \& Holden BA (1983). Corneal thickness profiles in rabbits using ultrasonic pachymeter. Investigative Ophthalmology and Visual Science, 24: 1408-1410.

12. Sharir M, Pierce Jr WM, Ochsner KI et al. (1993). Novel topical thiadiazoles and benzothiazoles as pharmacological probes of corneal endothelial function. Journal of Ocular Pharmacology, 9: 333340.

13. Geroski DH, Matsuda M, Yee RW et al. (1985). Pump function of the human corneal endothelium - effects of age and cornea guttata. Ophthalmology, 92: 759-763.

14. Edelhauser HF (2000). The resiliency of the corneal endothelium to refractive and intraocular surgery. Cornea, 19: 263-273.

15. Geroski DH, Edelhauser HF \& O'Brien WJ (1978). Hexose-monophosphate shunt response to diamide in the component layers of the cornea. Experimental Eye Research, 26: 611-619.

16. Fischbarg J \& Maurice DM (1997). An update on corneal hydration control. In: Lass JH (Editor), Advances in Corneal Research. Plenum Press, New York.

17. Pfeiffer N (1997). Dorzolamide: development and clinical application of a topical carbonic anhydrase inhibitor. Survey of Ophthalmology, 42: 137-151.

18. Van Der Bijl P, Engelbrecht AH, Van Eyk AD et al. (2002). Comparative permeability of human and rabbit corneas to cyclosporin and tritiated water. Journal of Ocular Pharmacology and Therapeutics, 18: 419-427.

19. Green K (1991). Corneal endothelial structure and function under normal and toxic conditions. Cell Biology Reviews, 25: 169-207.

20. Ojeda JL, Ventosa JA \& Piedra S (2001). The three-dimensional microanatomy of the rabbit and human cornea. A chemical and mechanical microdissection - SEM approach. Journal of Anatomy, 199: 567-576. 